\title{
Skeletal muscle insulin resistance in hamsters with diabetes developed from obesity is involved in abnormal skeletal muscle LXR, PPAR and SREBP expression
}

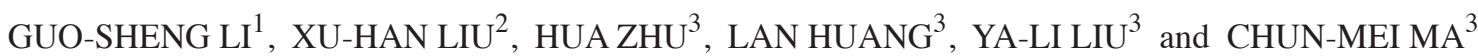 \\ ${ }^{1}$ Department of Pathology, The First Affiliated Hospital of Dalian Medical University, Dalian, Liaoning 116011; \\ ${ }^{2}$ Department of Endocrinology, Dalian Municipal Central Hospital, Dalian, Liaoning 116033; ${ }^{3}$ Department of Pathology, \\ Institute of Laboratory Animal Science, Chinese Academy of Medical Sciences (CAMS) and \\ Peking Union Medical College (PUMC), Beijing 100021, P.R. China
}

Received January 20, 2015; Accepted February 26, 2016

DOI: 10.3892/etm.2016.3209

\begin{abstract}
Diabetic 'lipotoxicity' theory suggests that fat-induced skeletal muscle insulin resistance (FISMIR) in obesity induced by a high-fat diet (HFD), which leads to ectopic lipid accumulation in insulin-sensitive tissues, may play a pivotal role in the pathogenesis of type 2 diabetes. However, the changes in gene expression and the molecular mechanisms associated with the pathogenesis of FISMIR have not yet been fully elucidated. In the present study the changes in skeletal muscle gene expression were examined in FISMIR in obese insulin-resistant and diabetic hamster models induced by HFD with or without low-dose streptozotocin-treatment. Microarray technology and reverse transcription-quantitative polymerase chain reaction (RT-qPCR) were used to explore the potential underlying molecular mechanisms. The pathophysiological and metabolic features of obesity and type 2 diabetes in humans are closely resembled by these hamster models. The results of microarray analysis showed that the differentially expressed genes associated with metabolism were mostly related to the abnormal regulation and changes in the gene expression of liver X receptor (LXR), peroxisome proliferator-activated receptor (PPAR) and sterol regulatory element-binding protein (SREBP) transcriptional programs in the skeletal muscle from insulin-resistant and diabetic hamsters. The microarray
\end{abstract}

Correspondence to: Dr Guo-Sheng Li, Department of Pathology, The First Affiliated Hospital of Dalian Medical University, 222 Zhongshan Road, Dalian, Liaoning 116011, P.R. China

E-mail: guoshengli998@163.com

Dr Xu-Han Liu, Department of Endocrinology, Dalian Municipal Central Hospital, 826 Xinan Road, Dalian, Liaoning 116033, P.R. China

E-mail: xuhanliu281277@hotmail.com

Key words: liver $\mathrm{X}$ receptors, peroxisome proliferator-activated receptors, sterol regulatory element-binding proteins, insulin resistance, type 2 diabetes findings confirmed by RT-qPCR indicated that the increased expression of SREBPs and LXR $\beta$ and the decreased expression of LXR $\alpha$ and PPARs were involved in the molecular mechanisms of FISMIR pathogenesis in insulin-resistant and diabetic hamsters. A significant difference in the abnormal expression of skeletal muscle LXRs, PPARs and SREBPs was found between insulin-resistant and diabetic hamsters. It may be concluded that the combined abnormal expression of LXR, PPAR and SREBP transcriptional programs may contribute to the development of FISMIR mediated by skeletal muscle lipid accumulation resulting from abnormal skeletal muscle glucose and lipid metabolism in these HFD- and streptozotocin injection-induced insulin-resistant and diabetic hamsters.

\section{Introduction}

Obesity-related resistance to the stimulatory effects of insulin on glucose utilization (insulin resistance) is central to the pathogenesis of type 2 diabetes mellitus and is an important contributor to the development of diabetes. Insulin resistance precedes the clinical development of type 2 diabetes (1). However, the mechanisms underlying the pathogenesis of insulin resistance of type 2 diabetes remain poorly understood at present. Obesity is widely recognized as a cause of type 2 diabetes and predisposes an individual to insulin resistance and type 2 diabetes. Obesity, which develops due to an imbalance between nutritional intake and energy expenditure, is characterized by an overabundance of nutrients leading to hypertrophy of storage cells in white adipose tissue and the deposition of excess lipids in key metabolic areas, for example skeletal muscle and liver, and in the circulation (2). Thus, the potential mechanism linking obesity with type 2 diabetes is ectopic lipid accumulation caused by abnormal lipid metabolism leading to 'lipotoxicity' in insulin-sensitive tissues, and ultimately resulting in fat-induced insulin resistance (3). Skeletal muscle is a peripheral insulin-sensitive tissue that accounts for $\sim 40 \%$ of total body weight and is a primary site of energy balance that accounts for $>30 \%$ of energy expenditure. Moreover, it is the primary tissue in which glucose uptake, disposal, storage and utilization occurs, and has a key role in 
insulin sensitivity, the blood lipid profile and lipid homeostasis, including fatty acid oxidation and cholesterol efflux. Therefore, skeletal muscle is important in both insulin-mediated glucose metabolism and in lipid metabolism (4). Skeletal muscle insulin resistance, associated with caloric excess, obesity and physical inactivity, mainly results from dyslipidemia and impaired fatty acid metabolism, specifically the intramuscular accumulation of fatty acid metabolites, which disrupt insulin signaling pathways via defective glucose uptake/phosphorylation to affect insulin action (5). Thus, obesity-related skeletal muscle insulin resistance is a hallmark of type 2 diabetes and a primary risk factor for promoting the development of type 2 diabetes. Furthermore, the molecular mechanisms involved in skeletal muscle insulin resistance, particularly fat-induced skeletal muscle insulin resistance (FISMIR) underlie the pathogenesis of obesity-related type 2 diabetes.

In the present study, hamsters with a genetic susceptibility for diabetes and exhibiting many features in common with lipid metabolism in humans were selected for the development of obese type 2 diabetes and obesity animal models as described by Li et al (6). In these models, feeding with a high-fat diet (HFD) feeding induces obesity (particularly visceral obesity), insulin resistance, hyperinsulinemia, 'deleterious' serum lipid level, and further augmentation of hyperglycemia following streptozotocin injection. Low-dose streptozotocin injection leads to hyperglycemia and a relative reduction of serum insulin levels. The pathophysiological and metabolic features of obesity-related insulin resistance and type 2 diabetes in these hamster models closely resemble those in human patients. An ideal and well-characterized animal model was thus used to study the mechanisms associated with the pathogenesis and therapy of type 2 diabetes. Microarray technology is an effective technique to explore the changes in complex gene expression profiles in diseases with a complex nature. Therefore, in the present study, changes in gene expression in skeletal muscle and the molecular mechanisms involved in the development of FISMIR in insulin-resistant and type 2 diabetic hamsters were explored using microarray technology. Characterizing the gene expression alterations and molecular mechanisms involved in FISMIR in obese insulin-resistant and type 2 diabetic states may offer new strategies and pharmacological targets for the prevention and treatment of peripheral insulin resistance associated with obesity-related type 2 diabetes.

\section{Materials and methods}

Animal model. A total of 35 five-month-old Golden Syrian hamsters, including 18 females and 17 males, weighing $125.1 \pm 10.5 \mathrm{~g}$, were purchased from the Sichuan Academy of Medical Sciences (Chengdu, China). All hamsters were maintained individually for 2 weeks under specific pathogen-free conditions at $18-25^{\circ} \mathrm{C}$ and $40-70 \%$ humidity, and under a $12-\mathrm{h}$ light/dark cycle with ad libitum access to standard laboratory chow and water. The hamster models of insulin resistance and diabetes were induced and grouped according to a previous study (6). Briefly, 25 hamsters, including 13 females and 12 males, were fed a high-fat diet consisting of $20 \%$ lard, $10 \%$ egg yolk powder, $1 \%$ cholesterol and $0.1 \%$ cholic acid [Institute of Laboratory Animal Science, Chinese Academy of
Medical Sciences (CAMS) and Peking Union Medical College (PUMC), Beijing, China] for 4 weeks to induce insulin resistance. The remaining hamsters were fed standard laboratory chow for 4 weeks. Subsequently, the insulin-resistant hamsters were randomly divided into two groups, as follows: Group 1 ( $n=15 ; 8$ females and 7 males), in which the hamsters were twice injected intraperitoneally with $40 \mathrm{mg} / \mathrm{kg}$ streptozotocin (Sigma-Aldrich, St. Louis, MO, USA) dissolved in vehicle ( $0.05 \mathrm{~mol} / \mathrm{l}$ citric acid, $\mathrm{pH} 4.5)$ to induce type 2 diabetes; and group 2 ( $n=10 ; 5$ females and 5 males), in which the hamsters were injected intraperitoneally with $4 \mathrm{ml} / \mathrm{kg}$ citric acid. Following treatment, the hamsters were maintained on the same diet for 2 weeks. The successful establishment of diabetic and insulin-resistant animals was assessed by the measurement of fasting blood glucose levels (diabetic animals $\geq 9 \mathrm{mmol} / \mathrm{l}$; OneTouch ${ }^{\circledR}$ UltraTM Blood Glucose Monitoring System; LifeScan International Inc., Milpitas, CA, USA) and oral glucose tolerance tests.

Following the induction of the two models, the hamsters were randomly selected and divided into three groups, including the control, insulin-resistant and type 2 diabetes groups ( $n=10 /$ group). After 6 weeks, the hamsters in the three groups were sacrificed after a $12 \mathrm{~h}$ fasting period by cervical dislocation following ether (Beijing Chemical works, Beijing, China) inhalation. Blood samples were obtained by retro-orbital sinus puncture under anesthesia with ether. The serum was separated by centrifugation at 3,000 x g for $20 \mathrm{~min}$ at $4^{\circ} \mathrm{C}$ and stored at $-80^{\circ} \mathrm{C}$ until used for determining metabolic and biochemical parameters. Skeletal muscle (soleus) was rapidly removed, weighed, frozen in liquid nitrogen and stored at $-80^{\circ} \mathrm{C}$ until analysis. All procedures involving animal handling and tissue harvesting were reviewed and approved by the Institute of Laboratory Animal Science, CAMS and PUMC Laboratory Animal Care and Use Committee and Institutional Animal Welfare Committee (Beijing, China).

Oral glucose tolerance tests (OGTTS). The hamsters were subjected to OGTTs following an overnight fast. Oral glucose load was administered at $2 \mathrm{~g} / \mathrm{kg}$. Blood samples were obtained under anesthesia with ether from the retro-orbital sinus at 0 , 30, 60, 120 and $180 \mathrm{~min}$ after glucose challenge and blood glucose and insulin levels were measured.

Blood chemistry testing. Serum concentrations of free fatty acids (FFAs), total cholesterol (TC), low density lipoprotein (LDL)-c, high density lipoprotein (HDL)-c and triglycerides (TGs) were analyzed using commercial kits (Randox Laboratories Ltd., Crumlin, UK) in accordance with the manufacturer's protocol, and a Hitachi 8060 automatic biochemical analyzer (Hitachi Co., Ltd, Tokyo, Japan). TC and TG levels were determined by CHOD-PAP and GPO-PAP colorimetric end-point assays, respectively, using Randox Total Cholesterol (cat. no., CH200) and Triglycerides (cat. no., TR1697) kits. FFAs were measured by the non-esterified fatty acids (NEFA) colorimetric method using a Randox NEFA kit (cat. no., FA115). HDL-c and LDL-c were quantified by a direct clearance method using Randox Direct HDL-c (cat. no., CH2652) and Direct LDL-c kits (cat. no., CH2656). Blood glucose was measured with a OneTouch ${ }^{\circledR}$ Ultra $^{\mathrm{TM}}$ Blood Glucose Monitoring System. Serum insulin and adiponectin 
levels were determined using a rat/mouse insulin kit (Linco; EMD Millipore, Billerica, MA, USA) and adiponectin enzyme-linked immunosorbent assay kit (cat. no. MRP300; R\&D Systems, Inc., Minneapolis, MN, USA) in accordance with the manufacturer's protocol.

Analysis of skeletal muscle lipid content. Skeletal muscle lipid accumulation was demonstrated by the analysis of skeletal muscle lipid content. Lipid content was measured essentially as described by Brown et al (7). Briefly, $100 \mathrm{mg}$ frozen skeletal muscle tissues from the different groups were minced and homogenized in $2 \mathrm{ml}$ sucrose buffer $(0.3 \mathrm{~mol} / 1$ sucrose, $25 \mathrm{nmol} / 1$ 2-mercaptoethanol, and $10 \mathrm{mmol} / 1$ EDTA, pH 7.0) and then mixed with chloroform/methanol, $2: 1$, vol/vol. The total lipid material was then extracted as follows: The organic phase was separated, dried, and the lipids resuspended in $100 \mu \mathrm{l}$ ethanol. TG and TC were measured, using the kits detailed above, according to the manufacturer's protocol.

Microarray analysis. Frozen skeletal muscle tissues from hamsters in each group were collected and total RNA was extracted using an RNeasy Mini kit (Qiagen GmbH, Hilden, Germany). After purification, the quantity and quality of total RNA were determined by spectrophotometry (SmartSpec ${ }^{\mathrm{TM}}$ Plus; Bio-Rad Laboratories, Inc., Hercules, CA, USA, Beijing, China). The quality of the RNA was determined by formaldehyde-agarose gel electrophoresis. Then, $5 \mu \mathrm{g}$ total RNA was reversely transcribed into cDNA using a cDNA Synthesis kit (Promega Corporation, Madison, WI, USA). After purification using NucleoSpin ${ }^{\circledR}$ RNA clean-up (Macherey-Nagel GmbH \& Co. KG, Düren, Germany), cRNA was synthesized from the cDNA using T7 RiboMAX Express Large Scale RNA Production System (Promega Corporation). A $2 \mu \mathrm{g}$ quantity of cRNA reverse-transcribed product was labeled with either $40 \mu \mathrm{mol} / 1 \mathrm{dCTP}-\mathrm{Cy} 5$ or $40 \mu \mathrm{mol} / 1 \mathrm{dCTP}-\mathrm{Cy} 3$ (Amersham Pharmacia Biotech, Inc., Piscataway, NJ, USA) and Klenow fragment (polymerase; Takara Biotechnology Co., Ltd., Dalian, China), 9 Random Primer, $60 \mu \mathrm{mol} / 1 \mathrm{dCTP}$, and 120 $\mu \mathrm{mol} / 1 \mathrm{dATP}, \mathrm{dGTP}$, dTTP in a $200-\mu 1$ final volume. The labeled cDNA was purified using a NucleoSpin Extract II kit (Macherey-Nagel GmbH \& Co. KG) and dried.

A 36k Mouse Genome Oligo Array (Operon Mouse Genome, version 4.0; http://www.operon.com) representing approximately 25,000 genes was printed in arrays on $75 \times 25 \mathrm{~mm}$ slides with the use of SmartArray ${ }^{\mathrm{TM}}$ (CapitalBio Corporation, Beijing, China). The manufacturer of the oligo array states that the high conservation of genome sequences and high likelihood of crossreactivity of genomic hybridization between mice and the hamsters make the use of a mouse microarray to hybridize with the hamster cDNA possible. The labeled cDNA $(0.9 \mu \mathrm{g})$ was added to $30 \mu \mathrm{g}$ hybridization solution containing $3 \mathrm{X}$ sodium chloride sodium citrate (SSC), $5 \mathrm{X}$ Denhart's solution, $25 \%$ formamide and $0.2 \%$ sodium dodecyl sulfate (SDS). The labeled cDNA in the hybridization solution was added to the microarray slide, and then hybridized to the microarray at $42^{\circ} \mathrm{C}$ for $12 \mathrm{~h}$. Following hybridization, the slides were washed at $42^{\circ} \mathrm{C}$ for $5 \mathrm{~min}$ in solution containing $2 \mathrm{X} \mathrm{SSC}$ and $0.2 \%$ $\mathrm{SDS}$, and then transferred to $0.2 \mathrm{X} \mathrm{SSC}$ at room temperature for $5 \mathrm{~min}$. Slides were then dried by centrifugation. The skeletal muscle (soleus) tissues from three hamsters of each group were randomly selected for microarray analysis. All experiments were performed in duplicate. Fluorescence intensities of microarray spots were measured using a laser double-channel LuxScan 10KA scanner (CapitalBio Corporation). Image analysis was performed using GenePix Pro 4.0 software (Axon Instruments, Inc.; Molecular Devices LLC, Sunny Vale, CA, USA). Then, Lowess normalization was applied to the primary data. After normalization, ratio values were calculated, and the differentially expressed genes (those with $>1.5$ - or $<1.5$-fold differences in expression between groups) were identified. Gene Ontology analyses were then performed using the Database for Annotation, Visualization and Integrated Discovery (v6.7) and EASE 2.0 (National Institute of Allergy and Infectious Diseases, Bethesda, MD, USA) in order to classify the differentially expressed genes according to function.

Reverse transcription-quantitative polymerase chain reaction $(R T-q P C R)$. For verification of the microarray analysis results, RT-qPCR analysis of selected genes was performed. Total RNA was extracted from frozen skeletal muscle tissues of hamsters from the different groups using an RNeasy Mini kit. The quantity and quality of total RNA were determined by spectrophotometry, and the integrity was assessed by $1 \%$ agarose gel electrophoresis. cDNA was synthesized from $1 \mu \mathrm{g}$ total RNA using an iScript cDNA Synthesis kit (Bio-Rad Laboratories, Inc.) in accordance with the manufacturer's protocol. Specific primers pairs for each gene were designed using Primer Express software v2.0 (Applied Biosystems; Thermo Fisher Scientific, Waltham, MA, USA) or obtained from previously published papers. Then, the reverse-transcribed products of $50 \mathrm{ng}$ total RNA were amplified with iQ Syber Green Supermix (Bio-Rad Laboratories, Inc.) according to the manufacturer's protocol using an iCycler iQ Real Time PCR Detection System (Bio-Rad Laboratories, Inc.). The amplification conditions were as follows: $95^{\circ} \mathrm{C}$ for $3 \mathrm{~min}$, followed by 45 cycles of $95^{\circ} \mathrm{C}$ for $10 \mathrm{sec}$ and $57^{\circ} \mathrm{C}$ for $45 \mathrm{sec}$. When the amplification process was completed, the reaction mixture was further subjected to 80 cycles of $0.5^{\circ} \mathrm{C}$ increments (10 sec each) beginning at $57^{\circ} \mathrm{C}$ for melting curve analysis to check the identity and purity of the amplified products. Each reaction was performed in triplicate. To ensure specific amplification, negative controls were included in the PCR reaction. qPCR efficiency measured prior to amplification was close to 1 . Thus the relative quantification for a target gene in a given sample was calculated according to the $2^{-\Delta \Delta \mathrm{Cq}}$ method (8). $\beta$-actin was used as the reference gene. The nucleotide sequences of the forward and reverse primers are presented in Table I.

Statistical analysis. Data are expressed as mean \pm standard deviation. Differences were assessed using two-tailed student's t-test and one-way analysis of variance. Statistical significance was considered as $\mathrm{P}<0.05$. Analyses were performed using SPSS for Windows software, version 13.0 (SPSS, Inc., Chicago, IL, USA).

\section{Results}

Metabolic characterization of insulin-resistant and diabetic hamsters. The insulin-resistant and type 2 diabetic hamsters 
Table I. Primers used for reverse transcription-quantitative polymerase chain reaction.

\begin{tabular}{|c|c|c|}
\hline Gene & Genbank accession no. & Forward/reverse primers \\
\hline Srebfla & NM_011480 & $\begin{array}{l}\text { 5'-ATGGACGAGCTGGCCTTCGGTGAGGCGGC-3' } \\
\text { 5'-CAGGAAGGCTTCCAGAGAGGA-3' }\end{array}$ \\
\hline Srepf1c & NM_011480 & $\begin{array}{l}\text { 5'-GCTGTTGGCATCCTGCTATC-3' } \\
\text { 5'-TAGCTGGAAGTGACGGTGGT-3' }\end{array}$ \\
\hline Srebf2 & U12330 & $\begin{array}{l}\text { 5'-AGCTGGCAAATCAGAAAAACAAG-3' } \\
\text { 5'-GATTAAAGTCTTCAATCTTCAAGTCCAC-3' }\end{array}$ \\
\hline Nr1h3 & AJ132601 & $\begin{array}{l}\text { 5'-TCAGCATCTTCTCTGCAGACCGG-3' } \\
\text { 5'-TCATTAGCATCCGTGGGAACA-3' }\end{array}$ \\
\hline $\mathrm{Nr} 1 \mathrm{~h} 2$ & NM_009473 & $\begin{array}{l}\text { 5'-AAGCAGGTGCCAGGGTTCT-3' } \\
\text { 5'-TGCATTCTGTCTCGTGGTTGT-3' }\end{array}$ \\
\hline Ppara & NM_011144 & $\begin{array}{l}\text { 5'-TGAGGAAGCCGTTCTGTGAC-3' } \\
\text { 5'-GGTGTCATCTGGATGGTTGC-3' }\end{array}$ \\
\hline Ppard & NM_011145 & $\begin{array}{l}\text { 5'-GCCTCGGGCTTCCACTAC-3' } \\
\text { 5'-AGATCCGATCGCACTTCTCA-3' }\end{array}$ \\
\hline Pparg & NM_011146 & $\begin{array}{l}\text { 5'-CCCCTGCTCCAGGAGATCTAC-3' } \\
\text { 5'-GCAATCAATAGAAGGAACACGTTGT-3' }\end{array}$ \\
\hline Hmgcr & X00494 & $\begin{array}{l}\text { 5'-AGATACTGGAGAGTGCCGAGAAA-3' } \\
\text { 5'-TTTGTAGGCTGGGATGTGCTT-3' }\end{array}$ \\
\hline Hmges & L00326 & $\begin{array}{l}\text { 5'-CCTGGGTCACTTCCTTTGAATG-3' } \\
\text { 5'-GATCTCAAGGGCAACGATTCC-3' }\end{array}$ \\
\hline Ldlr & NM_010700 & $\begin{array}{l}\text { 5'-CCAACCTGAAGAATGTGGTG-3' } \\
\text { 5'-CAGGTCCTCACTGATGATGG-3' }\end{array}$ \\
\hline Fasn & NM_007988 & $\begin{array}{l}\text { 5'-CACAGATGATGACAGGAGATGG-3' } \\
\text { 5'-TCGGAGTGAGGCTGGGTTGAT-3' }\end{array}$ \\
\hline Scd 1 & NM_009127 & $\begin{array}{l}\text { 5'-TGGGTTGGCTGCTTGTG-3' } \\
\text { 5'-GCGTGGGCAGGATGAAG-3' }\end{array}$ \\
\hline Acc & AF356089 & $\begin{array}{l}\text { 5'-ACACTGGCTGGCTGGACAG-3' } \\
\text { 5'-CACACAACTCCCAACATGGTG-3' }\end{array}$ \\
\hline $\mathrm{Cd} 36$ & NM_007643 & $\begin{array}{l}\text { 5'-GCCAAGCTATTGCGACATGA-3' } \\
\text { 5'-GATAGACCTGCAAATGTCAGAGGAA-3' }\end{array}$ \\
\hline Socs 3 & NM_007707 & $\begin{array}{l}\text { 5'-CACCTGGACTCCTATGAGAAAGTG-3' } \\
\text { 5'-GAGCATCATACTGATCCAGGAACT-3' }\end{array}$ \\
\hline Ptpn1 & NM_011201 & $\begin{array}{l}\text { 5'-GGCGTGGTCATGCTCAAC-3' } \\
\text { 5'-GCCAATACTGGGCACATTTTAA-3' }\end{array}$ \\
\hline Hk2 & NM_013820 & $\begin{array}{l}\text { 5'-GCACTGGAGAAGAGCTTTTCGA-3' } \\
\text { 5'-AGGGACACGCCCTTCATG-3' }\end{array}$ \\
\hline Acox & NM_053115 & $\begin{array}{l}\text { 5'-CCAGGACAGAGGTTCTTGGT-3' } \\
\text { 5'-TCTCAGGAAGGACTTGGCTT-3' }\end{array}$ \\
\hline Cpt1 & NM_013495 & $\begin{array}{l}\text { 5'-CTCAGTGGGAGCGACTCTTCA-3' } \\
\text { 5'-GGCCTCTGTGGTACACGACAA-3' }\end{array}$ \\
\hline Acadm & NM_007382 & $\begin{array}{l}\text { 5'-TGACGGAGCAGCCAATGA-3' } \\
\text { 5'-ATGGCCGCCACATCAGA-3' }\end{array}$ \\
\hline Adipor1 & NM_028320 & $\begin{array}{l}\text { 5'-AACGGGCCATCCATTTTTG-3' } \\
\text { 5'-TTAGCCGGGCTACATCAAGG-3' }\end{array}$ \\
\hline Pdk4 & NM_013743 & $\begin{array}{l}\text { 5'-CTGGTATATCCAGAGCCTGA-3' } \\
\text { 5'-GACCAGCGTGTCTACAAACT-3' }\end{array}$ \\
\hline Ucp3 & NM_009464 & $\begin{array}{l}\text { 5'-CATCACAAGAAATGCCATTGTCA-3' } \\
\text { 5'-TCCAGCAACTTCTCCTTGATGA-3' }\end{array}$ \\
\hline GSlc2a4 & NM_009204 & $\begin{array}{l}\text { 5'-TGCAAAGCGTAGGTACCAACAC-3' } \\
\text { 5'-CCGCCCTTAGTTGGTCAGAA-3' }\end{array}$ \\
\hline Ppargc1a & ВC066868 & $\begin{array}{l}\text { 5'-TCTGGAACTGCAGGCCTAACTC-3' } \\
\text { 5'-GCAAGAGGGCTTCAGCTTTG-3' }\end{array}$ \\
\hline Adipoq & NM_009605 & $\begin{array}{l}\text { 5'-GGGCTCAGGATGCTACTGTTG-3' } \\
\text { 5'-AGTAACGTCATCTTCGGCATGA-3' }\end{array}$ \\
\hline Lpl & NM_008509 & $\begin{array}{l}\text { 5'-GCCCAGCAACATTATCCAGT-3' } \\
\text { 5'-GGTCAGACTTCCTGCTACGC-3' }\end{array}$ \\
\hline Gys & U53218 & $\begin{array}{l}\text { 5'-CGATGGAAGGGTGAGCTTT-3' } \\
\text { 5'-GGTGGTGAGGAAGCTGTA-3' }\end{array}$ \\
\hline$\beta$-actin & AY618569 & $\begin{array}{l}\text { 5'-AGAGGGAAATCGTGCGTGAC-3' } \\
\text { 5'-CAATAGTGATGACCTGGCCGT-3' }\end{array}$ \\
\hline
\end{tabular}


Table II. Basal metabolic characterization of the control, insulin-resistant and diabetic groups after 6 weeks of treatment.

\begin{tabular}{|c|c|c|c|}
\hline Characteristic & Control group & Insulin-resistant group & Diabetic group \\
\hline Body weight (g) & $126.40 \pm 11.70$ & $148.00 \pm 9.00^{\mathrm{a}}$ & $146.10 \pm 10.68^{\mathrm{a}}$ \\
\hline SM weight (g) & $5.20 \pm 0.90$ & $5.90 \pm 0.85^{\mathrm{a}}$ & $6.00 \pm 0.60^{\mathrm{a}}$ \\
\hline \multicolumn{4}{|l|}{ Serum characteristics } \\
\hline Blood glucose (mg/dl) & $85.32 \pm 12.60$ & $120.24 \pm 16.29^{a}$ & $185.40 \pm 23.40^{\mathrm{a}, \mathrm{b}}$ \\
\hline Serum insulin (ng/ml) & $0.88 \pm 0.10$ & $1.90 \pm 0.21^{\mathrm{a}}$ & $1.36 \pm 0.20^{\mathrm{a}, \mathrm{b}}$ \\
\hline Serum adiponectin $(\mu \mathrm{g} / \mathrm{ml})$ & $30.18 \pm 6.49$ & $18.41 \pm 2.18^{\mathrm{a}}$ & $18.70 \pm 2.61^{\mathrm{a}}$ \\
\hline Serum triglyceride (mg/dl) & $175.23 \pm 31.86$ & $832.97 \pm 79.65^{\mathrm{a}}$ & $872.61 \pm 76.11^{\mathrm{a}}$ \\
\hline Serum FFAs (mmol/l) & $1.39 \pm 0.31$ & $6.60 \pm 0.91^{\mathrm{a}}$ & $7.03 \pm 1.12^{\mathrm{a}}$ \\
\hline Serum LDL (mmol/l) & $1.85 \pm 0.58$ & $11.30 \pm 1.65^{\mathrm{a}}$ & $12.55 \pm 1.58^{\mathrm{a}, \mathrm{b}}$ \\
\hline Serum HDL (mmol/l) & $1.55 \pm 0.28$ & $1.20 \pm 0.36^{\mathrm{a}}$ & $1.08 \pm 0.20^{\mathrm{a}}$ \\
\hline Serum total cholesterol $(\mathrm{mmol} / \mathrm{l})$ & $6.75 \pm 0.81$ & $14.69 \pm 2.54^{\mathrm{a}}$ & $15.78 \pm 2.88^{\mathrm{a}}$ \\
\hline \multicolumn{4}{|l|}{ SM lipid content (mg/g tissue) } \\
\hline Total cholesterol & $0.61 \pm 0.13$ & $1.42 \pm 0.26^{\mathrm{a}}$ & $1.46 \pm 0.23^{\mathrm{a}}$ \\
\hline Triglyceride & $4.31 \pm 0.63$ & $9.70 \pm 1.77^{\mathrm{a}}$ & $10.79 \pm 2.16^{\mathrm{a}}$ \\
\hline \multicolumn{4}{|l|}{ Index of insulin resistance } \\
\hline $\mathrm{G}_{0} \times \mathrm{I}_{0}^{\mathrm{c}}$ & $107.02 \pm 18.62$ & $318.65 \pm 76.38^{\mathrm{a}}$ & $379.40 \pm 82.90^{\mathrm{a}, \mathrm{b}}$ \\
\hline HOMA-IR ${ }^{d}$ & $4.91 \pm 0.93$ & $14.31 \pm 3.90^{\mathrm{a}}$ & $17.90 \pm 4.60^{\mathrm{a}, \mathrm{b}}$ \\
\hline
\end{tabular}

Data are presented as the mean \pm standard deviation $(n=10)$. ${ }^{a} \mathrm{P}<0.05$ vs. the control group. ${ }^{b} \mathrm{P}<0.05$ vs. the insulin-resistant group. ${ }^{\mathrm{c}} \mathrm{G}_{0} \mathrm{xI}$ : $\mathrm{G}_{0}$, fasting glucose (mmol/l); $\mathrm{I}_{0}$, fasting insulin (mU/l). ${ }^{\mathrm{d}} \mathrm{HOMA}-\mathrm{IR}$, fasting glucose (mmol/l) x fasting insulin (mU/l)/22.5. SM, skeletal muscle; FFAs, free fatty acids; LDL, low-density lipoprotein; HDL, high-density lipoprotein; HOMA-IR, homeostatic model assessment of insulin resistance.

were phenotypically and metabolically characterized as described by Li et al (6). At the end of the experiment, the skeletal muscle (soleus) weight was higher in the insulin-resistant and diabetic groups than in the control group. The serum adiponectin levels were significantly decreased in the insulin-resistant and diabetic groups compared with those in the control group (Table II).

Skeletal muscle lipid accumulation in insulin-resistant and diabetic hamsters. Skeletal muscle lipid content, specifically TG and TC content, was directly measured in the animal models. The results indicated that skeletal muscle TG and TC contents were significantly increased in the insulin-resistant and diabetic groups compared with those in the control group. Furthermore, a similar degree of lipid accumulation in the skeletal muscle was observed in insulin-resistant and diabetic hamsters (Table II).

Changes of skeletal muscle gene expression in insulin-resistant and diabetic hamsters. The results of the microarray analysis indicated that $4.1 \%(1,025)$ and $6.34 \%(1,585)$ of the assessed genes shown significant changes (1.5-fold upregulated or downregulated) in their mRNA levels in insulin-resistant and diabetic hamsters, respectively. The number of differentially expressed genes was higher in the diabetic group than in the insulin-resistant group.

In the insulin-resistant group, $2.3 \%$ (575) genes were upregulated, and 1.8\% (450) genes were downregulated among 1,025 differentially expressed genes. In the diabetic group, $3.5 \%$ (875) genes exhibited increased expression, and $2.84 \%$ (710) exhibited decreased expression among 1,585 differentially expressed genes. The results of Gene Ontology analysis indicated that in the insulin resistant and diabetic groups, 208 and 242 differentially expressed metabolism-related genes associated with diabetes were involved in skeletal muscle lipid metabolism, glucose metabolism, hormonally regulated signaling pathways and certain transcription/nuclear factors. Among the 208 and 242 genes, there were a total of 143 differentially expressed genes, including 67 upregulated ( $>1.5$-fold) and 76 downregulated $(<1.5$-fold) genes, that were identified in both groups, a partial list of which is presented in Table III. However, the remaining differentially expressed genes were upregulated in only the insulin-resistant group (27 genes) or diabetic group (47 genes) and downregulated in only the insulin-resistant group (38 genes) or diabetic group (52 genes; Fig. 1).

Abnormal gene expression of skeletal muscle key regulators and target genes in insulin-resistant and diabetic hamsters. The data presented in Table III show that the expression levels of sterol regulatory element-binding protein (SREBP) genes, specifically SREBP-1 (also known as Srebf1) and SREBP-2 (also known as Srebf2), were upregulated in the insulin-resistant and diabetic groups compared with the control group. Target genes of SREBP-1c implicated in fatty acid synthesis, such as fatty acid synthase (Fasn), acetyl-coenzyme A carboxylase (Acc) and stearoyl-CoA desaturase-1 (Scd1), and transport, namely fatty acid transporter (FAT), also known as Cd36, exhibited increased expression, and target genes of SREBP-2 involved in cholesterol metabolism, including 3-hydroxy-3-methylglutaryl coenzyme A synthase (Hmgcs), HMG CoA reductase (Hmgcr) and low density lipoprotein receptor (Ldlr) were also upregulated in the insulin-resistant and diabetic groups.

The expression levels of liver $\mathrm{X}$ receptor $\beta$ (LXR $\beta)$, also known as Nr1h2, were increased in the insulin-resistant and diabetic groups compared with the control group. In addition, 
Table III. Partial list of the upregulated ( $>1.5$-fold) or downregulated $(<1.5$-fold) skeletal muscle genes associated with glucose and lipid metabolism identified by microarray analysis in insulin-resistant and diabetic groups compared with control group.

\begin{tabular}{|c|c|c|c|c|}
\hline $\begin{array}{l}\text { Genbank } \\
\text { accession no. }\end{array}$ & Gene name (symbol) & $\begin{array}{l}\text { IR group } \\
\text { (fold change) }\end{array}$ & $\begin{array}{l}\text { DM group } \\
\text { (fold change) }\end{array}$ & Regulator \\
\hline NM_007988 & Fatty acid synthase (Fasn) & 1.84 & 3.57 & SREBP-1 \\
\hline BE865030 & Acetyl-coenzyme A carboxylase (Acc) & 1.75 & 3.04 & SREBP-1 \\
\hline NM_009127 & Stearoyl CoA desaturase $1(S c d l)$ & 1.88 & 3.64 & SREBP-1 \\
\hline NM_007643 & CD36 antigen $(C d 36)$ & 1.96 & 3.69 & SREBP-1 \\
\hline NM_053115 & Acyl-coenzyme A oxidase (Acox) & -2.88 & -3.55 & $\operatorname{PPAR} \alpha$ \\
\hline NM_013495 & Carnitine palmitoyltransferase 1 , liver $(C p t 1)$ & -2.83 & -3.53 & $\operatorname{PPAR} \alpha, \operatorname{PPAR} \beta$ \\
\hline NM_007382 & $\begin{array}{l}\text { Acetyl-coenzyme A dehydrogenase, medium } \\
\text { chain }(\text { Acadm })\end{array}$ & -2.57 & -3.23 & $\operatorname{PPAR} \alpha$ \\
\hline NM_028320 & Adiponectin receptor 1 (Adipor1) & -2.42 & -3.21 & $\operatorname{PPAR} \alpha$ \\
\hline BM937289 & $\begin{array}{l}\text { 3-Hydroxy-3-methylglutaryl-coenzyme A } \\
\text { reductase (Hmgcr) }\end{array}$ & 1.74 & 2.73 & SREBP-2 \\
\hline NM_145942 & $\begin{array}{l}\text { 3-hydroxy-3-methylglutaryl-Coenzyme A } \\
\text { synthase (Hmgcs) }\end{array}$ & 1.84 & 3.95 & SREBP-2 \\
\hline NM_010700 & Low density lipoprotein receptor $(L d l r)$ & 2.36 & 3.26 & SREBP-2 \\
\hline NM_011480 & $\begin{array}{l}\text { Sterol regulatory element binding factor } 1 \\
(\text { Srebfl) }\end{array}$ & 1.94 & 2.90 & $\mathrm{LXR} \alpha$ \\
\hline XM_127995 & $\begin{array}{l}\text { Sterol regulatory element binding factor } 2 \\
(\text { Srebf } 2)\end{array}$ & 1.76 & 2.49 & Unknown \\
\hline NM_013839 & $\begin{array}{l}\text { Nuclear receptor subfamily } 1 \text {, group } \mathrm{H} \text {, } \\
\text { member } 3(\mathrm{Nr} 1 \mathrm{~h} 3)\end{array}$ & -2.26 & -2.99 & $\mathrm{LXR} \alpha$ \\
\hline NM_009473 & $\begin{array}{l}\text { Nuclear receptor subfamily } 1 \text {, group } \mathrm{H} \text {, } \\
\text { member } 2(N r 1 h 2)\end{array}$ & 2.39 & 2.87 & Unknown \\
\hline NM_011144 & $\begin{array}{l}\text { Peroxisome proliferator activated receptor } \\
\alpha(\text { Ppara })\end{array}$ & -2.74 & -3.75 & Unknown \\
\hline NM_011145 & $\begin{array}{l}\text { Peroxisome proliferator activator receptor } \\
\delta(\text { Ppard })\end{array}$ & -2.46 & -3.19 & Unknown \\
\hline NM_011146 & $\begin{array}{l}\text { Peroxisome proliferator activated receptor } \\
\gamma \text { (Pparg) }\end{array}$ & -2.37 & -3.31 & $\mathrm{LXR} \alpha$ \\
\hline NM_008509 & Lipoprotein lipase $(L p l)$ & -2.15 & -3.17 & $\operatorname{PPAR} \gamma$ \\
\hline NM_009605 & $\begin{array}{l}\text { Adiponectin, } \mathrm{C} 1 \mathrm{Q} \text { and collagen } \\
\text { domain containing (Adipoq) }\end{array}$ & -2.32 & -3.11 & PPAR $\gamma$ \\
\hline NM_008904 & $\begin{array}{l}\text { Peroxisome proliferative activated receptor, } \\
\text { gamma, coactivator } 1 \alpha(\text { Pargcla })\end{array}$ & -2.02 & -3.04 & $\operatorname{PPAR} \gamma$ \\
\hline NM_009204 & $\begin{array}{l}\text { Solute carrier family } 2 \text { (facilitated glucose } \\
\text { transporter), member } 4 \text { (Slc2a4) }\end{array}$ & -2.42 & -3.44 & $\operatorname{PPAR} \gamma / \beta$ \\
\hline NM_009464 & $\begin{array}{l}\text { Uncoupling protein } 3 \text { (mitochondrial, } \\
\text { proton carrier) }(U c p 3)\end{array}$ & -2.62 & -3.41 & $\operatorname{PPAR} \beta, \mathrm{LXR} \alpha$ \\
\hline NM_013743 & $\begin{array}{l}\text { Pyruvate dehydrogenase kinase, } \\
\text { isoenzyme } 4(P d k 4)\end{array}$ & -2.36 & -3.15 & $\operatorname{PPAR} \beta$ \\
\hline NM_007707 & Suppressor of cytokine signaling 3 (Socs 3 ) & 2.49 & 2.97 & $\mathrm{LXR} \alpha$ \\
\hline NM_011201 & $\begin{array}{l}\text { Protein tyrosine phosphatase, non-receptor } \\
\text { type } 1 \text { (Ptpn1) }\end{array}$ & 2.28 & 3.99 & $\mathrm{LXR} \alpha$ \\
\hline NM_013820 & Hexokinase $2(H k 2)$ & -2.35 & -3.29 & $\operatorname{LXR} \alpha$ \\
\hline U53218 & Glycogen synthase $(G y s)$ & -2.27 & -3.51 & Unknown \\
\hline
\end{tabular}

Fold change in gene-expression level relative to control is shown and represents the mean value, with negative numbers indicating decreased fold change. The Regulator column shows whether the gene is predominantly regulated by SREBPs, LXRs and PPARs in the subsequent analysis. IR group (fold change), insulin-resistant group vs. control group (fold change); DM group (fold change), diabetic group vs. control group (fold change). SREBP, sterol regulatory element-binding protein; LXR, liver X receptor; PPAR, peroxisome proliferator-activated receptor.

the expression of suppressor of cytokine signaling 3 (Socs3) and protein tyrosine phosphatase, non-receptor type 1 (Ptpn1), also known as protein-tyrosine phosphatase 1B (PTP-1B), which are regulated by $\mathrm{LXR} \alpha$, also known as $\mathrm{Nr} 1 \mathrm{~h} 3$, were also increased in the insulin-resistant and diabetic groups compared with the control group. Furthermore, the increase in the expression of the aforementioned genes was higher in the diabetic group than in the insulin-resistant group. 
A significant downregulation was observed in LXR $\alpha$ (Nr1h3) and peroxisome proliferator-activated receptor (PPAR) mRNA levels, specifically PPAR $\alpha, \operatorname{PPAR} \beta / \delta$ and PPAR $\gamma$ (also known as Ppara, Ppard and Pparg, respectively) levels, in the insulin-resistant and diabetic groups. The expression levels of PPAR $\alpha$ target genes, such as acyl-CoA oxidase (Acox), carnitine-palmitoyl transferase 1 (Cpt1), medium-chain acyl-CoA dehydrogenase (Acadm) and adiponectin receptor 1 (Adipor1) were also downregulated. Furthermore, the gene expression levels of pyruvate dehydrogenase kinase 4 (Pdk4), Cpt1, glucose transporter-4 (GLUT4, also known as Slc2a4) and uncoupling protein-3 (Ucp3) regulated by PPAR $\beta / \delta$ also decreased. In addition, in comparison with the control group, the expression levels of genes regulated by PPAR $\gamma$, including peroxisome proliferator-activated receptor $\gamma$ coactivator- $1 \alpha$ (Ppargcla, also known as PGC-1 $\alpha$ ), lipoprotein lipase (Lpl), Slc2a4 and adiponectin (Adipoq) were decreased in the insulin-resistant and diabetic groups. The expression of genes regulated by $\mathrm{LXR} \alpha$, such as PPAR $\gamma, \mathrm{Ucp} 3$ and hexokinase II (Hk2) was also decreased in the insulin-resistant and diabetic groups. In addition, glycogen synthase (Gys) mRNA levels were decreased in the insulin-resistant and diabetic groups compared with the control groups .Furthermore, the reductions in the expression of the aforementioned genes were greater in the diabetic group than in the insulin-resistant group.

Confirmation of the expression of skeletal muscle SREBPs, LXRs and PPARs and certain target genes by RT-qPCR in insulin-resistant and diabetic hamsters. In order to confirm the changes in gene expression for SREBPs, LXRs and PPARs and certain of their target genes in insulin-resistant and diabetic hamsters, 29 key genes including SREBPs, LXRs and PPARs were chosen for further investigation by RT-qPCR analysis. A significant increase in the SREBP (SREBP-1a, SREBP-1c and SREBP-2) and LXR $\beta$ mRNA levels and a significant reduction in the LXR $\alpha$ and PPAR (PPAR $\alpha$, PPAR $\beta / \delta$ and PPAR $\gamma$ ) mRNA levels were observed in the insulin-resistant and diabetic groups (Fig. 2A). The expression levels of Fasn, Acc, Scd1, Cd36/FAT, Ldlr, Hmgcs, Hmgcr, Socs3 and Ptpn1 were also significantly increased, while the expression levels of Gys, Hk2, Acox, Cpt1, Acadm, Adipor1, Pdk4, Ucp3, Slc2a4, Ppargcla, Lpl and Adipoq were significantly decreased in both the insulin-resistant and diabetic groups compared with the control group (Fig. 2B-D). In addition, significant differences in the levels of expression of SREBPs, LXRs and PPARs and their target genes were identified between the insulin-resistant and diabetic groups. Not all of the results obtained by micoarray hybridization were confirmed by RT-qPCR. Thus, in the present study only the verified data were considered suitable for interpretation. A unique combination of abnormal gene expression patterns of SREBPs, LXRs and PPARs was observed in FISMIR in insulin-resistant and diabetic states.

\section{Discussion}

In subjects at high-risk of type 2 diabetes mellitus, one of the earliest detectable abnormalities is skeletal muscle insulin resistance, which is a critical defect in type 2 diabetes (9). Although the precise cause of skeletal muscle insulin resistance associated with type 2 diabetes remains unknown, there

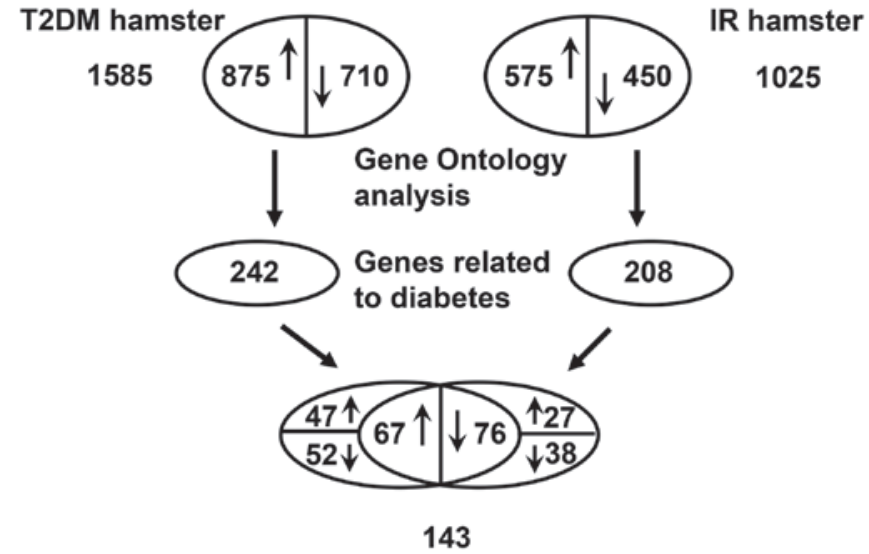

Figure 1. Numbers of up- or down-regulated genes in the insulin-resistant and diabetic groups compared with the control group. The overlapping region denotes the number of common genes up- or down-regulated in the insulin-resistant and diabetic groups. The nonoverlapping region denotes the number of unique genes up- or down-regulated in insulin-resistant and diabetic groups. T2DM, type 2 diabetes; IR, insulin resistant.

is known to be a strong association between insulin resistance and lipid accumulation in skeletal muscle, in particular, lipotoxic fatty acid metabolite accumulation, which results in the insulin-stimulated glucose uptake being reduced (10). Evidence suggests that high-fat feeding (dyslipidemia) induces skeletal muscle insulin resistance by altering lipid metabolism in skeletal muscle, associated with an imbalance between fatty acid uptake and oxidation, and resulting in intramuscular lipid accumulation (lipotoxicity) (11). The potential mechanisms underlying the biogenesis of intramyocellular ectopic lipid accumulation are a focus of research interest. Studies have suggested that the local accumulation of lipid metabolites, including ceramides, diacylglycerol or acyl-CoA, inside skeletal muscle, may activate a serine kinase cascade involving PKC $\theta$ and reduce insulin-stimulated insulin receptor substrate 1-(IRS-1)- and IRS-2-associated phosphoinositide 3-kinase activity leading to defects in insulin signaling and glucose transport $(12,13)$. Although the molecular mechanisms of FISMIR have been studied, the changes in gene expression in the skeletal muscle gene and the molecular mechanisms involved in FISMIR, that is, how intramuscular lipid accumulation leads to insulin resistance, are not completely known. In the present study, microarray analysis showed that a variety of genes involved in the regulation of lipid and glucose metabolism were dysregulated in skeletal muscle tissues from obese insulin-resistant and type 2 diabetic hamsters. These results indicate that insulin-resistant state is associated with defects in the control of transcriptional programs of lipid and glucose metabolism, causing intramuscular lipid accumulation in skeletal muscle tissue before and after the onset of diabetes. These results also suggest that the combined abnormal expression of SREBPs, LXRs and PPARs and their target genes may be involved in molecular mechanisms of FISMIR in obese insulin-resistant and type 2 diabetic hamsters by increasing skeletal muscle lipid metabolite content (lipotoxicity) associated with abnormal skeletal muscle glucose and lipid metabolism (Fig. 3).

The results indicate that the expression of skeletal muscle LXR $\alpha$, Hk2, Ucp3, GLUT4 and PPAR $\gamma$ significantly 
A
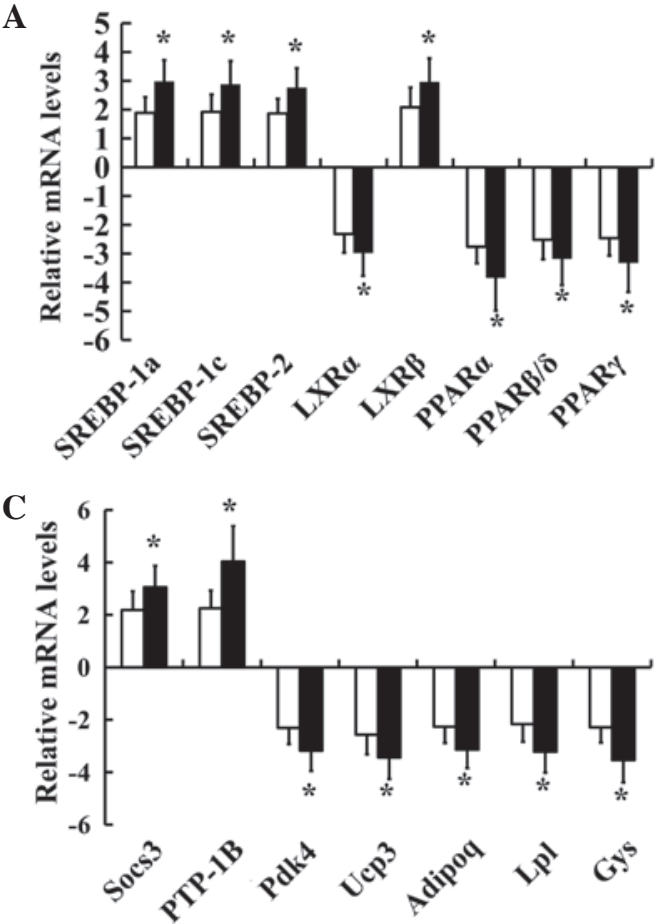

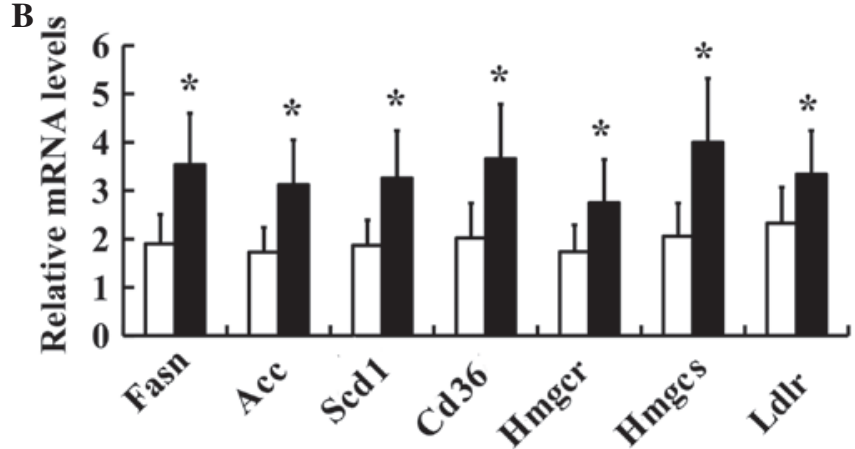

D

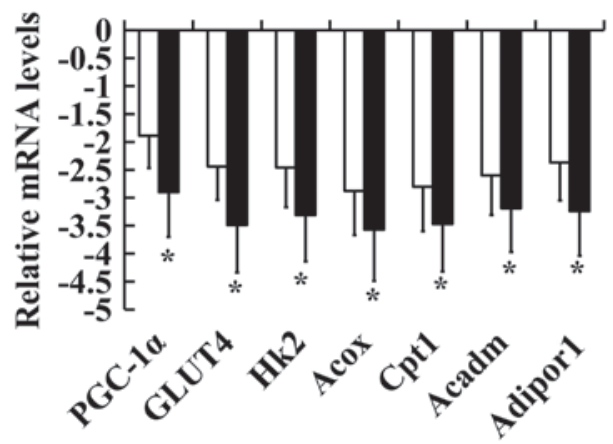

Figure 2. Relative quantification of differentially expressed skeletal muscle sterol regulatory element-binding proteins (SREBPs), liver X receptors (LXRs) and peroxisome proliferator-activated receptors (PPARs) and certain of their target genes in the insulin-resistant group compared with the diabetic group. (A) Relative quantification of skeletal muscle SREBP-1a, SREBP-1c, SREBP-2, LXR $\alpha$, LXR $\beta$, PPAR $\alpha$, PPAR $\beta$ and PPAR $\gamma$ mRNA levels in the insulin-resistant group (open bars) vs. the diabetic group (solid bars). (B-D) Relative quantification of target gene mRNA levels in the insulin-resistant group (open bars) vs. the diabetic group (solid bars). Relative quantification in gene-expression levels relative to the control are shown. Values are presented as mean \pm standard deviation $(\mathrm{n}=10)$. ${ }^{*} \mathrm{P}<0.05$ vs. the insulin-resistant group.

decreased but the expression of skeletal muscle LXR $\beta$, Socs3 and PTP-1B significantly increased in insulin-resistant and diabetic hamsters. Such changes in skeletal muscle gene expression imply that reduced LXR $\alpha$ expression was not sufficient to suppress skeletal muscle Socs3 and PTP-1B gene expression, which contributed to the development of skeletal muscle insulin resistance $(14,15)$, and also was not effective in inducing skeletal muscle $\mathrm{Hk} 2$ expression to promote skeletal muscle glucose utilization. Defects in $\mathrm{Hk} 2$ function could directly contribute to the development of skeletal muscle insulin resistance and type 2 diabetes (16). In addition, the results demonstrated that the reduced expression of LXR $\alpha$ attenuated its ability to effectively induce the expression of GLUT4, Ucp3 and PPAR $\gamma$ to prevent or attenuate skeletal muscle insulin resistance by increasing insulin-mediated skeletal muscle glucose import, thermogenesis, and the beneficial effect of PPAR $\gamma$ expression and activation on insulin resistance (17), which is discussed in the following text. Thus, it is implied that the reduced expression of $\mathrm{LXR} \alpha$ might contribute to skeletal muscle lipid accumulation associated with abnormal skeletal muscle glucose and lipid metabolism, and the development of FISMIR. In addition, skeletal muscle LXR $\beta$, the mRNA levels of which increased, appears to be involved in inducing the gene expression of SREBPs to increase the lipogenetic and cholestrogenic activities of skeletal muscle $(18,19)$ that contribute to skeletal muscle lipid accumulation and the development of FISMIR in these models. The results demonstrate that these two nuclear receptors, LXR $\alpha$ and LXR $\beta$, have an interdependent regulatory relationship, in addition to each being involved in the control of metabolic fuel usage. Thus, it appears that the reduced expression of $\mathrm{LXR} \alpha$, increased expression of $\mathrm{LXR} \beta$ and changes in the expression of their target genes contributed to the abnormal skeletal muscle glucose and lipid metabolism, skeletal muscle lipid accumulation and development of FISMIR and obesity-related diabetes observed in these insulin-resistant and type 2 diabetic hamsters.

In the present study, the expression of skeletal muscle SREBPs (SREBP-1a, SREBP-1c and SREBP-2), Fasn, Acc, Scd1, Cd36/FAT, Ldlr, Hmges and Hmger significantly increased in insulin-resistant and diabetic hamsters. The overexpression of skeletal muscle SREBPs was perhaps induced by increased expression of LXR $\beta$ directly and by hyperinsulinemia resulting from a HFD and hyperglycemia through a Janus kinase/signal transducer and activator of transcription dependent pathway indirectly (20). However, the reduced LXR $\alpha$ expression does not appear to be associated with induction of SREBP overexpression in skeletal muscle. Thus, with respect to induction of SREBP overexpression, the LXR isomers, LXR $\alpha$ and LXR $\beta$, exhibited different actions. Among SREBP isomers, activated overexpression of SREBP-1c drives the transcription of genes involved in de novo lipogenesis, such as Acc, Scd1, Fasn, and fatty acid transport (Cd36/FAT), and regulates the TG storage content in the skeletal muscle (21). Thus, overexpression of SREBP-1c might contribute to the development of skeletal muscle lipid accumulation that leads to skeletal muscle insulin resistance by increasing lipid synthesis and the influx of fatty acids into muscle cells. Furthermore, the increased skeletal muscle lipid accumulation could lead to $\mathrm{Hk} 2$ inhibition, thereby contributing to skeletal muscle insulin resistance (22). Activated overexpression of SREBP-2 contributes to enhanced 


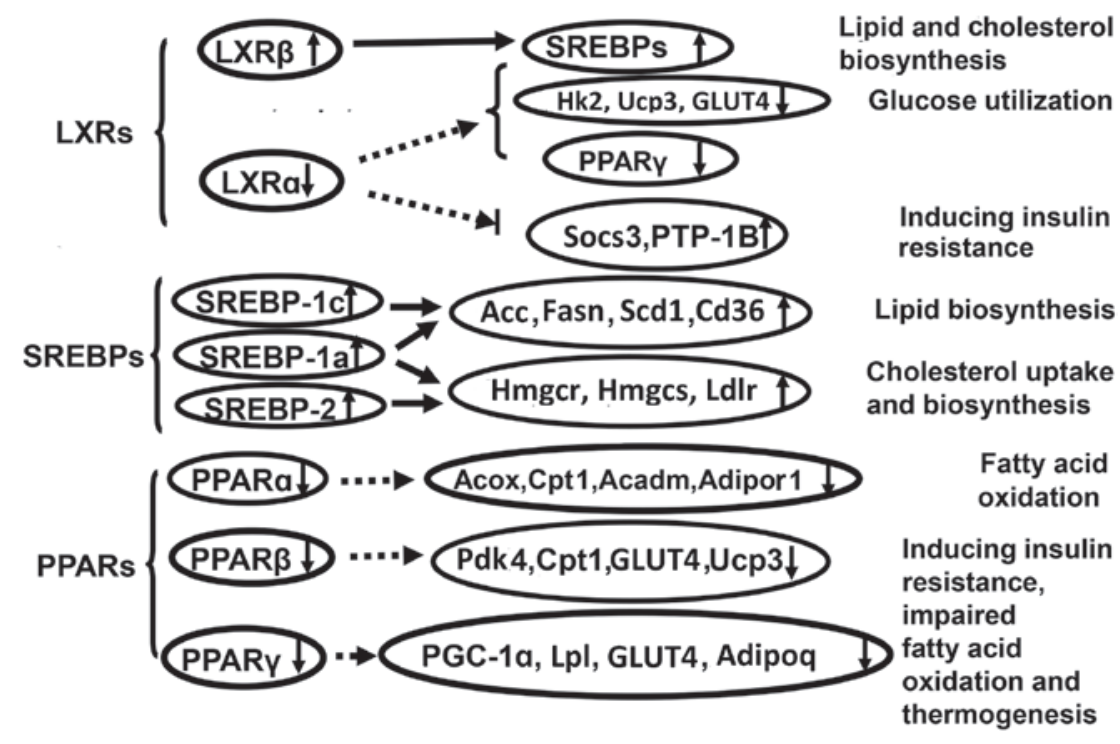

Regulators

Target genes

Biological effects

Figure 3. Metabolic effects of sterol regulatory element-binding proteins (SREBPs), liver X receptors (LXRs) and peroxisome proliferator-activated receptors (PPARs). A simplified model of potential regulatory mechanisms of SREBPs, LXRs and PPARs underlying the induction of fat-induced skeletal muscle insulin resistance in insulin-resistant and diabetic hamsters is shown. Solid line arrows indicate enhanced stimulatory effects, and dotted line arrows indicate weakened stimulatory or inhibitory effects. LXR $\alpha$ induces skeletal muscle glucose utilization, glucose uptake, thermogenesis and the expression of PPAR $\gamma$ and inhibits the expression of Socs 3 and PTP-1B. LXR $\beta$ induces lipogenesis. SREBPs induce lipid and cholesterol biosynthesis. PPAR $\alpha$ induces skeletal muscle fatty acid oxidation and Adiporl expression. PPAR $\beta$ induces glucose uptake, lipid utilization, fatty acid oxidation and thermogenesis. PPAR $\gamma$ induces glucose uptake, biogenesis of mitochondria and the production of adiponectin.

skeletal muscle cholesterol uptake and biosynthesis by driving the expression of genes including Ldlr, Hmges and Hmgcr (23). The overexpression of SREBP-1a exhibits the ability to induce skeletal muscle lipogenesis and cholesterogenesis (24). Thus, it is implied that the overexpression of SREBPs and their target genes might lead to the abnormal skeletal muscle glucose and lipid metabolism and skeletal muscle lipid accumulation that contributes to FISMIR in insulin-resistant and type 2 diabetic hamsters. In addition, the results of the present study indicate that the increased expression of SREBP-1c is not involved in the inductive effect of hyperinsulinemia on $\mathrm{Hk} 2$ gene transcription in the skeletal muscle of insulin-resistant and diabetic hamsters', unlike the inductive mechanisms of hyperinsulinemia on $\mathrm{Hk} 2$ gene transcription mediated by SREBP-1c observed in the normal state $(25,26)$.

The expression of skeletal muscle PPARs (PPAR $\alpha$, PPAR $\beta / \delta$ and PPAR $\gamma$ ), Acox, Cpt1, Acadm, Adipor1, Pdk4, Ucp3, GLUT4, PGC-1 $\alpha, \mathrm{Lpl}$ and Adipoq was significantly decreased in the insulin-resistant and diabetic hamsters of the present study. Firstly, such alterations in the expression of skeletal muscle PPAR $\alpha$ and its target genes suggest that the reduced expression of skeletal muscle PPAR $\alpha$ did not effectively drive the transcription of genes, such as Acox, Cpt1 and Acadm, involved in the peroxisomal and mitochondrial oxidation of fatty acids. Additionally, the reduced expression of skeletal muscle PPAR $\alpha$ did not effectively induce the expression of its target gene Adiporl and so did not activate AMP-activated protein kinase (AMPK) to stimulate fatty acid combustion in skeletal muscle, thereby contributing to skeletal muscle lipid accumulation $(27,28)$. Decreased adiponectin action mediated by reduced Adiporl expression could cause obesity-linked insulin resistance by adverse interactions with other factors $(28,29)$.
Our previous study has indicated that the reduced expression of PPAR $\alpha$ and fatty acid oxidation-related genes, such as Acox, occur before the development of lipid accumulation (6). Thus, decreased skeletal muscle PPAR $\alpha$ expression contributes to skeletal muscle lipid accumulation and FISMIR.

The reduced expression of skeletal muscle PPAR $\beta / \delta$ and its target genes, including Pdk4, Cpt1, Ucp3 and GLUT4, contributes to the development of FISMIR by decreasing lipid utilization, fatty acid $\beta$-oxidation, energy expenditure and glucose transport. The decreased Ucp3 expression suggests that these insulin-resistant and diabetic hamsters have impaired HFD-induced (lipotoxic) thermogenesis (30). Finally, the reduced expression of skeletal muscle PPAR $\gamma$ and its target genes, such as PGC-1 $\alpha, \mathrm{Lpl}$, Adipoq and GLUT4, also contribute to the development of FISMIR. The reduced expression of PPAR $\gamma$ is not likely to have induced the gene expression of glutathione peroxidase (GPx3), which, therefore, would not reduce the extracellular $\mathrm{H}_{2} \mathrm{O}_{2}$ levels causing insulin resistance in skeletal muscle (31). A reduction in the expression of Lpl in skeletal muscle contributes to insulin resistance in other key metabolic tissues and ultimately leads to systemic insulin resistance (32).

The reduced expression of PGC-1 $\alpha$, one of target genes of PPAR $\gamma$, results in a reduction in the biogenesis of mitochondria, respiration and muscle oxidative phenotype, which contributes to skeletal muscle lipid accumulation and FISMIR (33). The decreased expression of adiponectin may abolish its ability to activate AMPK and/or increase the transcriptional activity of PPAR $\alpha$ and its target genes in skeletal muscle to stimulate fatty acid combustion $(28,34)$. Adiponectin when expressed at low levels, would lost the ability to suppress the expression of SREBP-1c through the adiponectin/liver 
kinase B1/AMPK pathway $(28,35)$. Thus, the decreased expression of adiponectin contributes to skeletal muscle lipid accumulation associated with the development of FISMIR. Therefore, it appears that the reduced expression of skeletal muscle PPARs and PPAR-responsive genes leads to a reduction of skeletal muscle fatty acid $\beta$-oxidation and contributes to abnormal skeletal muscle glucose and lipid metabolism and skeletal muscle lipid accumulation, subsequently causing deteriorated skeletal muscle insulin resistance.

In conclusion, the metabolic characteristics and clinical syndromes of obesity-related insulin resistance and type 2 diabetes exhibited in the hamster models induced by a HFD and streptozotocin treatment were partially due to the combined abnormal expression of skeletal muscle SREBP, LXR and PPAR transcriptional programs. In addition, the results of the present study also demonstrate that the decreased expression of two main steps among all three major steps in non-oxidative glucose processing, namely glucose transport (GLUT4) and phosphorylation (Hk2), and glycogen synthesis (Gys) was regulated by the combined abnormal expression of skeletal muscle LXR, PPAR and SREBP transcriptional programs in the skeletal muscle of insulin-resistant and type 2 diabetic hamsters, which might be implicated as major defects responsible for causing insulin resistance. The changes in these gene transcriptional programs could partially explain the association between obesity induced by a HFD, abnormal skeletal muscle glucose and lipid metabolism, and skeletal muscle lipid accumulation contributing to the occurrence and development of skeletal muscle insulin resistance and overt type 2 diabetes. Thus, it appears that associations exist among disturbed skeletal muscle glucose and lipid metabolism, skeletal muscle lipid accumulation, FISMIR and type 2 diabetes.

\section{Acknowledgements}

The authors would like to thank Kerang Shou and Hong Gao for assistance with the animal experiments and technical help. They also thank Hao Yang of the Beijing Proteome Research Center and Xiaobing Zhang of CapitalBio Corporation (Beijing, China).

\section{References}

1. Anandharajan R, Sayyed SG, Doshi LS, Dixit P, Chandak PG, Dixit AV, Brahma MK, Deshmukh NJ, Gupte R, Damre A, et al: 18F9 (4-(3,6-bis (ethoxycarbonyl)-4,5,6,7-tetrahydrothieno (2,3-c)pyridin-2-ylamino)-4-oxobutanoic acid) enhances insulin-mediated glucose uptake in vitro and exhibits antidiabetic activity in vivo in db/db mice. Metabolism 58: 1503-1516, 2009.

2. Guri AJ, Hontecillas R and Bassaganya-Riera J: Dietary modulators of peroxisome proliferator-activated receptors: Implications for the prevention and treatment of metabolic syndrome. J Nutrigenet Nutrigenomics 1: 126-135, 2008.

3. Unger RH and Orci L: Lipotoxic diseases of nonadipose tissues in obesity. Int J Obes Relat Metab Disord 24 (Suppl 4): S28-S32, 2000.

4. Smith AG and Muscat GE: Skeletal muscle and nuclear hormone receptors: Implications for cardiovascular and metabolic disease. Int J Biochem Cell Biol 37: 2047-2063, 2005.

5. Guilherme A, Virbasius JV, Puri V and Czech MP: Adipocyte dysfunctions linking obesity to insulin resistance and type 2 diabetes. Nat Rev Mol Cell Biol 9: 367-377, 2008.

6. Li G, Liu X, Zhu H, Huang L, Liu Y, Ma C and Qin C: Insulin resistance in insulin-resistant and diabetic hamsters (Mesocricetus auratus) is associated with abnormal hepatic expression of genes involved in lipid and glucose metabolism. Comp Med 59: 449-458, 2009.
7. Brown MS, Faust JR and Goldstein JL: Role of the low density lipoprotein receptor in regulating the content of free and esterified cholesterol in human fibroblasts. J Clin Invest 55: 783-793, 1975.

8. Livak KJ and Schmittgen TD: Analysis of relative gene expression data using real-time quantitative PCR and the 2(-Delta Delta C(T)) method. Methods 25: 402-408, 2001.

9. Patti ME, Butte AJ, Crunkhorn S, Cusi K, Berria R, Kashyap S, Miyazaki Y, Kohane I, Costello M, Saccone R, et al: Coordinated reduction of genes of oxidative metabolism in humans with insulin resistance and diabetes: Potential role of PGC1 and NRF1. Proc Natl Acad Sci USA 100: 8466-8471, 2003.

10. Dumas JF, Simard G, Flamment M, Ducluzeau PH and Ritz P: Is skeletal muscle mitochondrial dysfunction a cause or an indirect consequence of insulin resistance in humans? Diabetes Metab 35: 159-167, 2009.

11. Mullen KL, Pritchard J, Ritchie I, Snook LA, Chabowski A, Bonen A, Wright D and Dyck DJ: Adiponectin resistance precedes the accumulation of skeletal muscle lipids and insulin resistance in high-fat-fed rats. Am J Physiol Regul Integr Comp Physiol 296: R243- R251, 2009.

12. Mauvais-Jarvis F, Clegg DJ and Hevener AL: The role of estrogens in control of energy balance and glucose homeostasis. Endocr Rev 34: 309-338, 2013

13. Choi CS, Fillmore JJ, Kim JK, Liu ZX, Kim S, Collier EF, Kulkarni A, Distefano A, Hwang YJ, Kahn M, et al: Overexpression of uncoupling protein 3 in skeletal muscle protects against fat-induced insulin resistance. J Clin Invest 117: 1995-2003, 2007.

14. Nieto-Vazquez I, Fernández-Veledo S, de Alvaro C and Lorenzo M: Dual role of interleukin-6 in regulating insulin sensitivity in murine skeletal muscle. Diabetes 57: 3211-3221, 2008.

15. Tsou RC and Bence KK: The genetics of PTPN1 and obesity: Insights from mouse models of tissue-specific PTP1B deficiency. J Obes 2012: 926857, 2012.

16. Heikkinen S, Suppola S, Malkki M, Deeb SS, Jänne J and Laakso M: Mouse hexokinase II gene: Structure, cDNA, promoter analysis and expression pattern. Mamm Genome 11: 91-96, 2000.

17. Norris AW, Hirshman MF, Yao J, Jessen N, Musi N, Chen L, Sivitz WI, Goodyear LJ and Kahn CR: Endogenous peroxisome proliferator-activated receptor-gamma augments fatty acid uptake in oxidative muscle. Endocrinology 149: 5374-5383, 2008.

18. Hessvik NP, Boekschoten MV, Baltzersen MA, Kersten S, Xu X, Andersén H, Rustan AC and Thoresen GH: LXR\{beta\} is the dominant LXR subtype in skeletal muscle regulating lipogenesis and cholesterol efflux. Am J Physiol Endocrinol Metab 298: E602-E613, 2010.

19. Zhu R, Ou Z, Ruan X and Gong J: Role of liver X receptors in cholesterol efflux and inflammatory signaling. Mol Med Rep 5: 895-900, 2012

20. Guillet-Deniau I, Pichard AL, Koné A, Esnous C, Nieruchalski M, Girard J and Prip-Buus C: Glucose induces de novo lipogenesis in rat muscle satellite cells through a sterol-regulatory-element-b nding-protein-1c-dependent pathway. J Cell Sci 117: 1937-1944, 2004.

21. Yahagi N, Shimano H, Hasty AH, Matsuzaka T, Ide T, Yoshikawa T, Amemiya-Kudo M, Tomita S, Okazaki H, Tamura Y, et al: Absence of sterol regulatory element-binding protein-1 (SREBP-1) ameliorates fatty livers but not obesity or insulin resistance in Lep(ob)/Lep(ob) mice. J Biol Chem 277: 19353-19357, 2002.

22. Thompson AL and Cooney GJ: Acyl-CoA inhibition of hexokinase in rat and human skeletal muscle is a potential mechanism of lipid-induced insulin resistance. Diabetes 49: 1761-1765, 2000

23. Yen CF, Jiang YN, Shen TF, Wong IM, Chen CC, Chen KC, Chang WC, Tsao YK and Ding ST: Cloning and expression of the genes associated with lipid metabolism in Tsaiya ducks. Poult Sci 84: 67-74, 2005.

24. Liang G, Yang J, Horton JD, Hammer RE, Goldstein JL and Brown MS: Diminished hepatic response to fasting/refeeding and liver $\mathrm{X}$ receptor agonists in mice with selective deficiency of sterol regulatory element-binding protein-1c. J Biol Chem 277: 9520-9528, 2002.

25. Kruszynska YT, Mulford MI, Baloga J, Yu JG and Olefsky JM: Regulation of skeletal muscle hexokinase II by insulin in nondiabetic and NIDDM subjects. Diabetes 47: 1107-1113, 1998.

26. Gosmain Y, Lefai E, Ryser S, Roques M and Vidal H: Sterol regulatory element-binding protein-1 mediates the effect of insulin on hexokinase II gene expression in human muscle cells. Diabetes 53: 321-329, 2004 
27. Whitehead JP, Richards AA, Hickman IJ, Macdonald GA and Prins JB: Adiponectin - a key adipokine in the metabolic syndrome. Diabetes Obes Metab 8: 264-280, 2006.

28. Almabouada F, Diaz-Ruiz A, Rabanal-Ruiz Y, Peinado JR, Vazquez-Martinez R and Malagon MM: Adiponectin receptors form homomers and heteromers exhibiting distinct ligand binding and intracellular signaling properties. J Biol Chem 288: 3112-3125, 2013.

29. Yamauchi $\mathrm{T}$ and Kadowaki T: Physiological and pathophysiological roles of adiponectin and adiponectin receptors in the integrated regulation of metabolic and cardiovascular diseases Int J Obes (Lond) 32 (Suppl 7): S13-S18, 2008.

30. Muscat GE and Dressel U: Cardiovascular disease and PPARdelta: Targeting the risk factors. Curr Opin Investig Drugs 6: 887-894, 2005.

31. Chung SS, Kim M, Youn BS, Lee NS, Park JW, Lee IK, Lee YS, Kim JB, Cho YM, Lee HK and Park KS: Glutathione peroxidase 3 mediates the antioxidant effect of peroxisome proliferator-activated receptor gamma in human skeletal muscle cells. Mol Cell Biol 29: 20-30, 2009.
32. Wang H, Knaub LA, Jensen DR, Young Jung D, Hong EG, Ko HJ, Coates AM, Goldberg IJ, de la Houssaye BA, Janssen RC, et al: Skeletal muscle-specific deletion of lipoprotein lipase enhances insulin signaling in skeletal muscle but causes insulin resistance in liver and other tissues. Diabetes 58 : 116-124, 2009.

33. Choi CS, Befroy DE, Codella R, Kim S, Reznick RM, Hwang YJ, Liu ZX, Lee HY, Distefano A, Samuel VT, et al: Paradoxical effects of increased expression of PGC-1alpha on muscle mitochondrial function and insulin-stimulated muscle glucose metabolism. Proc Natl Acad Sci USA 105: 19926-19931, 2008.

34. Kadowaki $\mathrm{T}$ and Yamauchi T: Adiponectin and adiponectin receptors. Endocr Rev 26: 439-451, 2005.

35. Awazawa M, Ueki K, Inabe K, Yamauchi T, Kaneko K, Okazaki Y, Bardeesy N, Ohnishi S, Nagai R and Kadowaki T: Adiponectin suppresses hepatic SREBP1c expression in an AdipoR1/LKB1/AMPK dependent pathway. Biochem Biophys Res Commun 382: 51-56, 2009. 